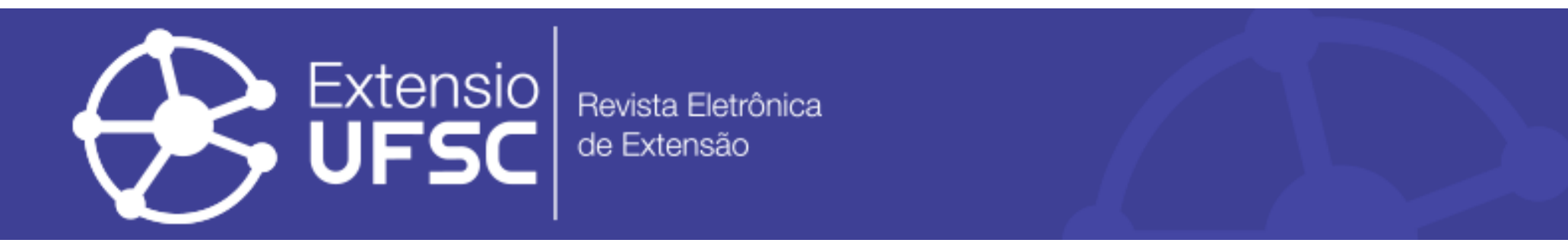

\title{
A EDUCAÇÃO PERMANENTE PROTAGONIZADA PELO IDOSO NA UNIVERSIDADE ABERTA PARA A TERCEIRA IDADE/UEPG
}

\author{
Rita de Cássia da Silva Oliveira \\ Universidade Estadual de Ponta Grossa \\ soliveira13@uol.com.br
}

\author{
Paola Andressa Scortegagna \\ Universidade Estadual de Ponta Grossa \\ paola_scortegagna@hotmail.com \\ Flávia Oliveira Alves da Silva \\ Universidade Estadual de Ponta Grossa \\ flasoliveira@uol.com.br
}

\section{Resumo}

A pirâmide etária brasileira registra um envelhecimento populacional. Evidencia-se hoje o Paradigma do Envelhecimento Ativo, no qual a educação assume relevância. As universidades brasileiras têm oferecido projetos/programas específicos para o idoso, que são as Universidades Abertas para a Terceira Idade (UATI). Concentram-se na valorização do idoso, colocando-o no centro do processo educativo. Este artigo objetiva apresentar o Programa da UATI/Universidade Estadual de Ponta Grossa (UEPG) criado em1992; explicitar os objetivos e a estrutura desta ação extensionista. Esta pesquisa foi bibliográfica e documental. A UATI baseia-se em 4 eixos articuladores, oferece disciplinas teóricas e práticas, nas diferentes áreas do conhecimento, totalizando 240 horas. O programa da UATI é composto pelos Cursos da Universidade Aberta para a Terceira idade e o Curso da Universidade Continuada para a Terceira Idade. A UATI é um programa de sucesso e reconhecimento social e acadêmico, nos seus 26 anos de atividades.

Palavras-chave: Educação Permanente. Políticas Públicas. Universidade Aberta para a Terceira Idade.

\section{THE PERMANENT EDUCATION PROTAGONIZED BY THE ELDERLY IN THE OPEN UNIVERSITY FOR THE THIRD AGE/UEPG}

\begin{abstract}
The Brazilian age pyramid shows an aging population. The Active Aging Paradigm is now evident, in which education assumes relevance. Brazilian universities have offered specific projects / programs for the elderly, which are Open Universities for the Elderly. They focus on valuing the elderly, placing them at the center of the educational process. This article aims to present the UATI / UEPG Program; explain the objectives and structure of this extensionist action. This research was bibliographical and documentary. The State University of Ponta Grossa created the UATI in 1992. The UATI is based on 4 articulating axes, offers theoretical and practical disciplines in the different areas of knowledge, totaling 240 hours. The UATI program consists of the Open University Courses for the Elderly and the Continuing University Course for the Elderly. UATI is a program of success and social and academic recognition in its 26 years of activities.
\end{abstract}

Keywords: Permanent Education. Public Policy. Open University for the Elderly.

\section{LA EDUCACIÓN PERMANENTE PROTAGONIZADA POR EL ADULTO MAYOR EN LA UNIVERSIDAD ABIERTA PARA LA TERCERA EDAD/UEPG}

\footnotetext{
Resumen

La pirámide de edad brasileña registra un envejecimiento poblacional. Se evidencia hoy el Paradigma del Envejecimiento Activo, en el cual la educación asume relevancia. Las universidades brasileñas han ofrecido proyectos / programas específicos para el anciano, que son las Universidades Abiertas para la Tercera Edad. Se concentran en la valorización del anciano, colocándolo en el centro del proceso educativo. Este artículo tiene por objeto presentar el Programa de la UATI / UEPG; explicitar los objetivos y la estructura de esta acción extensionista. Esta investigación fue bibliográfica y documental. La Universidad Estatal de Ponta Grossa creó la UATI en 1992. La UATI se basa en 4 ejes articuladores, ofrece disciplinas teóricas y prácticas, en las diferentes áreas del conocimiento, totalizando 240 horas. El programa de la UATI está compuesto por los Cursos de la Universidad Abierta para la Tercera edad y el Curso de la Universidad Continuada para la Tercera Edad. La UATI es un programa de éxito y reconocimiento social y académico, en sus 26 años de actividad.

Palabras clave: Educación Permanente. Políticas Públicas. Universidad Abierta para la Tercera Edad.
} 
A educação permanente protagonizada pelo idoso na universidade aberta para a terceira idade/UEPG

\section{PARA INÍCIO DE CONVERSA}

O processo de envelhecimento humano constitui uma realidade mundial. Este fenômeno também é evidenciado no Brasil, o qual ocorre com certa rapidez, impactando na estrutura do país nos diferentes aspectos: social, econômico, político, cultural e educacional.

Esse novo panorama atribui-se ao aumento da expectativa de vida (de 1950 até os tempos atuais, registra-se um aumento de 19 anos na expectativa de vida em todo mundo), a melhoria das condições de saúde decorrentes de avanços farmacológicos no controle de doenças infectocontagiosas (vacinas, antibióticos), melhorias na alimentação, diminuição dos índices de mortalidade e de natalidade, proporcionando um aumento significativo no contingente de idosos.

Essa realidade se confirma por meio das estatísticas, registrando em nosso país atualmente $13 \%$ da população, cerca de 26 milhões de pessoas com 60 anos ou mais, idade que é considerada idoso pelo Estatuto do Idoso (Lei 10.741/2003). Assim, este segmento merece e necessita cada vez mais atenção por parte dos órgãos públicos. Em uma projeção do Instituto Brasileiro de Geografia e Estatística (2013), em 2050 um quinto da população mundial será de idosos, ou seja, cerca de 1,9 bilhão de pessoas, equivalendo à população infantil de 0 a 14 anos de idade (MACHADO, POMPÉU, 2016).

Este cenário, num primeiro momento, surge como otimista por possibilitar mais longevidade para um maior número de pessoas, entretanto, em uma reflexão mais detalhada e minuciosa, percebe-se que esta nova realidade demográfica registra novas demandas na busca de ações que possibilitem uma melhoria na qualidade de vida desta faixa etária.

O fato de um maior número de pessoas estarem vivendo mais tempo e com qualidade, constitui um dos grandes desafios deste século. O crescimento desacelerado do Brasil "não se constitui em um mito de explosão demográfica, mas de uma realidade comprovada por dados numéricos de um envelhecimento populacional para um país que ilusoriamente carrega o sonho de país jovem e não se prepara para a realidade já comprovada” (OLIVEIRA, 1999, p,129).

Percebe-se a falta de informação, de consciência crítica e reflexiva sobre este processo de envelhecimento e sobre a quantidade de idosos na população, o que pode contribuir para o aumento de preconceitos pautados na falta de conhecimento.

\footnotetext{
Infelizmente ainda existe no discurso da Gerontologia a referência da velhice como "problema" ou doença", reforçando atitudes negativas, estereotipadas e preconceituosas em relação ao idoso e que na grande maioria não apresentam fundamentação científica. (OLIVEIRA, OLIVEIRA, SCORTEGAGNA, 2012, p.11).
} 
A educação permanente protagonizada pelo idoso na universidade aberta para a terceira idade/UEPG

Torna-se imprescindível o debate sobre as questões de envelhecimento e da fase da velhice como questão prioritária, em especial para o entendimento sobre os impactos que acarreta este novo perfil demográfico na sociedade, superar o plano teórico e das ideias para o plano prático, com ações efetivas para atender as necessidades deste segmento populacional. Esta preocupação deve ser da sociedade como um todo, tanto da política como da civil e não ser uma questão social apenas referenciada e colocada em pauta em época eleitoreira ou com interesses políticos.

Ao mesmo tempo em que se evidencia o aumento significativo dos idosos, também se percebe uma mudança no perfil destes idosos o que possibilita o esboço de um novo paradigma de velhice, protagonizado por um idoso mais ativo e participativo.

Atualmente, busca-se consolidar o Paradigma do Envelhecimento Ativo, que se constitui fundamentalmente na superação dos estereótipos negativos e marginalizadores atribuídos aos idosos. Estas mudanças se refletem num perfil distinto de idosos, sendo pessoas devido aos avanços no campo da saúde e da prevenção, tendem a desfrutar com mais qualidade de vida a própria velhice.

Neste novo paradigma, a educação assume relevância na medida em que oferece oportunidade de atualização e reflexões que possibilitam o empoderamento do idoso, contribuindo para um processo de envelhecimento mais saudável e com qualidade de vida. $\mathrm{O}$ conhecimento passa a ser um instrumento eficiente e necessário na tentativa de superar os desequilíbrios sociais e o conceito negativo culturalmente construído e consolidado em nossa sociedade.

Este artigo objetiva refletir sobre o papel da educação no empoderamento do idoso e a contribuição para a amplitude e consolidação do Paradigma do Envelhecimento Ativo. Objetiva também apresentar o Programa da UATI/UEPG; explicitar os objetivos e a estrutura desta ação extensionista.

\section{A EXTENSÃo E A EDUCAÇÃo PERMANENTE}

A universidade, sendo por excelência uma instituição responsável pela produção e disseminação de conhecimentos, assume as funções de pesquisa, ensino e extensão. Paralelamente, a universidade não pode desconsiderar as mudanças demográficas da população, estimulando estudiosos e pesquisadores para as reflexões e debates na busca de alternativas e estratégias educacionais para a melhoria das condições de vida dos idosos.

Conforme afirmam Oliveira, Scortegagna e Oliveira (2015, p.22) 
As ações extensionistas emergem a partir de questões sociais. Havendo a necessidade de buscar alternativas para a transformação da realidade de diferentes sujeitos. Para que isto seja possível, cabe a aproximação da academia com a comunidade, a fim de promover a relação entre o saber teórico e científico com o saber popular e a cultura, tendo como finalidade melhorar a qualidade de vida das pessoas, no sentido amplo.

A extensão universitária, enquanto função das universidades volta-se para estender ao maior número de pessoas os recursos e conhecimentos acumulados na universidade, articula a universidade com a sociedade, contribuindo para o desenvolvimento cultural, social, educacional, científico e tecnológico.

Um dos grupos que têm tido uma maior amplitude de atenção e atendimento em relação às ações extensionistas é o dos idosos, com uma expressiva quantidade de programas/projetos para a educação deste segmento da população.

Se, de um lado, compete à universidade, na sua função extensionista, socializar conhecimentos, difundindo-os na comunidade e se convertendo em uma força capaz de propiciar a elevação do nível cultural geral da sociedade, possibilitando melhores condições de vida, por outro lado, o empoderamento no Brasil, nos anos de 1990, constituiu como objetivo a busca da promoção do desenvolvimento social, abrindo assim espaço para a consolidação de diferentes intervenções práticas voltadas para o idoso, entre elas os Cursos/projetos voltados para a terceira idade (OLIVEIRA, SCORTEGAGNA, OLIVEIRA, 2015, p.33)

Em cumprimento ao Estatuto do Idoso e respeitando o direito à educação prescrito pela Constituição, são oferecidas pelas universidades, diferentes ações extensionistas como alternativas de atendimento ao idoso, pautadas na valorização e maior respeito ao processo do envelhecimento da população.

Segundo Oliveira, Scortegagna e Oliveira (2015, p.35)

A extensão voltada à terceira idade, nas universidades, apresenta um propósito bem definido: o empoderamento e a melhoria da qualidade de vida. Assim, as ações extensionistas buscam ressignificar os sentidos dados à própria existência, bem como ampliar as relações sociais dos sujeitos, seja no grupo em que estão inseridos seja em outros grupos sociais.

As ações extensionistas educacionais voltadas para a terceira idade fundamentam-se na concepção da educação permanente. A educação permanente baseia-se na ideia de que os indivíduos aprendem sempre, ao longo da vida porque a educação é um processo e nunca cessa. Trata-se de uma nova concepção de vida humana, no qual um dos princípios é aprender a ser e viver para aprender, inserindo-se no contexto e acompanhando todas as mudanças e evoluções sociais, tecnológicas e científicas. 
A educação permanente protagonizada pelo idoso na universidade aberta para a terceira idade/UEPG

Ao considerar que todo indivíduo aprende ao longo de sua trajetória de vida, pode-se considerar também o caráter transformador da educação, superando a ideia de que se limita à transmissão formal de conhecimentos, em espaços institucionais, como a escola.

A educação existe em diferentes espaços, sendo assim, existe a educação informal, a educação não-formal e a educação formal. Assim, a pessoa aprende em suas vivências no cotidiano, na interação com outras pessoas, mesmo sem uma sistematização ou intencionalidade, caracterizando a educação informal, sendo a família o principal agente socializador.

A educação não-formal possui intencionalidade, sistematização e uma flexibilidade mais ampla respeitando o tempo e o ritmo de aprendizagem e em diferentes espaços educativos. Nessa modalidade, que se enquadram a maioria dos programas e projetos voltados para o idoso. Já, a educação formal, volta-se para a educação escolarizada, com um currículo posto, com objetivos definidos, com uma estrutura e sistematização regulamentados por regras e legislações específicas.

A educação permanente perpassa as três modalidades e vai além, porque acompanha o indivíduo deste seu nascimento até a sua morte. Segundo Mosquera (1975, p.141) a "educação permanente é universal no seu caráter e essencial à completa democratização da aprendizagem, caracterizada pela sua flexibilidade e diversidade em conteúdos, apreendendo elementos, técnicas e finalidades abertas ao tempo e ao espaço".

Oliveira, Scortegagna e Oliveira (2015, p.87) afirmam que

A educação permanente se apresenta como a necessidade de ampliar a participação dos indivíduos na vida social e cultural, visando à melhoria nas relações interpessoais, qualidade de vida, compreendendo o mundo e tendo esperança de futuro. Pela educação permanente assume-se uma nova concepção de vida humana, cujo princípio central não é só aprender a ser, mas principalmente viver para aprender, interagindo com quem está ao seu redor.

Por meio da aquisição de conhecimentos, o idoso se instrumentaliza, se atualiza e se torna mais inserido e participativo na sociedade.

As ações extensionistas voltadas para o idoso são diversificadas, projetos, cursos, programas, mas convergem para a valorização do idoso, além de despertar a conscientização da sociedade em geral e dar maior visibilidade para o processo do envelhecimento e da velhice.

\section{UNIVERSIDADE ABERTA PARA A TERCEIRA IDADE (UATI) NA UEPG: uma ação extensionista de sucesso}

As primeiras universidades abertas para a terceira idade surgiram na França, nos anos de 1970 e inspiraram diferentes países inclusive o Brasil. 
A educação permanente protagonizada pelo idoso na universidade aberta para a terceira idade/UEPG

As UATIs são projetos, programas e cursos voltados para o idoso, com princípios educativos, que superaram a condição assistencialista, a fim de estimular o desenvolvimento do sujeito, para que seja mais participativo nas suas relações pessoais e sociais.

Diante da demanda social do envelhecimento, as UATI "podem ser consideradas como uma iniciativa inovadora, entendendo a inovação como atos, ações, alternativas diferenciadas, criativas e conscientes, diante de situações demandadas pelo próprio dinamismo da sociedade" (SILVA, VERGARA, SILVA, 2015, p. 64-65).

A UATI na UEPG foi criada em 1992, consistindo na primeira ação desta natureza no Paraná. Foi aprovada pelo Colegiado Setorial em 20/12/1991; homologado pelo Conselho de Ensino, Pesquisa e Extensão pelo Parecer 23 de 14/04/1992. O grande sucesso deste curso levou a Universidade Estadual de Ponta Grossa a institucionalizá-lo em 1997, sob a Resolução C.A. número 56. Desde esta data, a oferta deste programa (à época projeto) sócio educacional se tornou ininterrupta e sistemática.

No ano de 2012, o projeto da UATI, pelo seu reconhecimento acadêmico e social, foi reestruturado e transformado em programa, devido aos benefícios que trouxe para os idosos de Ponta Grossa e região, refletido em seu crescimento quanti-qualitativo. Desta forma, o Programa Universidade Aberta para a Terceira Idade está composto por cursos: Universidade Aberta para a Terceira idade (UATI) e Universidade Continuada para a Terceira Idade (UCTI), além de projetos e disciplinas distribuídos em 4 eixos norteadores, os quais contemplam as diferentes dimensões do ser humano.

Por meio deste programa, buscam-se propiciar o desenvolvimento de diferentes habilidades e competências, a ampliação de conhecimentos, relações intergeracionais, troca de saberes, inserção e participação social dos idosos.

A UATI/UEPG estrutura-se com abordagem multidisciplinar, que prioriza o processo de valorização humana e social deste segmento etário, refletindo de maneira contínua sobre as problemáticas do idoso sob as mais diversas abordagens: biológica, psicológica, sociológica, filosófica, política, espiritual, religiosa, econômica e cultural.

Dentro da sua organização, a UATI possui como objetivos:

- melhorar a qualidade de vida;

- valorizar o idoso;

- resgatar a dignidade e a cidadania do idoso;

- promover a participação e a integração do idoso;

- ampliar o convívio social do idoso;

- possibilitar o convívio intergeracional; 
A educação permanente protagonizada pelo idoso na universidade aberta para a terceira idade/UEPG

- possibilitar a aquisição de conhecimentos e a atualização;

- elevar a auto-estima do idoso;

- desenvolver as funções universitárias (ensino, pesquisa e extensão).

$\mathrm{Na}$ medida em que o idoso se insere no cotidiano das atividades universitárias, intensifica a integração entre gerações e possibilita reflexões e questionamentos sobre as representações sociais acerca da velhice, os preconceitos e discriminações que são cristalizados socialmente.

O Programa UATI estrutura-se em quatro grandes eixos articuladores: Educação, cultura e arte; Saúde, nutrição e qualidade de vida; Educação física, esporte e lazer; Direito, empoderamento e cidadania. Nestes eixos, baseiam-se e organizam-se os cursos (UATI e UCTI) e os projetos. Em cada eixo articulador estão alocadas as diferentes disciplinas.

Dentro de cada eixo há projetos e subprojetos, nos quais estão alocadas as atividades realizadas para os idosos, totalizando 240 horas, ao longo de três semestres letivos, seguindo o calendário universitário.

\section{EDUCAÇÃO, CULTURA E ARTE}

O primeiro eixo que estrutura o Programa UATI entende a educação como um processo contínuo e formativo, voltada à aquisição de conhecimentos e informações, por meio do qual ele se instrumentaliza e internaliza a cultura da sociedade a qual pertence.

A educação se constitui como um produto ideológico, ao mesmo tempo em que ela produz, também transmite cultura. "Mas essa transmissão da cultura pela educação, justamente porque supõe a mediação (dialética) da sociedade, na realidade, pelo trabalho concreto dos homens, não é mecânica, e por isso o saber não se comunica inalterado de um indivíduo ao outro" (PINTO, 2010, p. 43).

A UATI considera cultura como um conjunto de manifestações humanas coletivas; significa o aprimoramento das faculdades superiores do homem: inteligência, vontade, memória, associadas à educação, formação escolar e estudo, referindo-se também ao acesso às manifestações artísticas (pintura, teatro, escultura, música) e aos meios de comunicação de massa (televisão, rádio, cinema, jornais e revistas).

A cultura pode ser interpretada como construção da cidadania, fortalecendo a autonomia e a emancipação dos indivíduos. Um dos aspectos essenciais no processo de acesso aos bens culturais é o respeito às individualidades, valorizando as diversidades.

A arte é uma expressão cultural, possibilita o desenvolvimento da percepção, da sensibilidade, da crítica e da criatividade. 
A educação permanente protagonizada pelo idoso na universidade aberta para a terceira idade/UEPG

A cultura e a arte promovem nos idosos a valorização pessoal, o reconhecimento e desenvolvimento das potencialidades que ainda estão adormecidas, fazendo cada um perceber-se a si mesmo e as relações com os outros ao seu entorno.

Neste eixo, há o desenvolvimento das artes visuais, cênicas e música, além das questões culturais e educacionais. Estão alocadas as disciplinas de: Pintura em Tela, Teatro, Seresta, Artesanato, Inglês, Espanhol, Francês e Aulas teóricas.

Dentro deste eixo existe em desenvolvimento o Projeto Contador de Histórias.

\section{SAÚDE, NUTRIÇÃO E QUALIDADE DE VIDA}

O segundo eixo do Programa da UATI volta-se para as questões relativas à saúde, nutrição e qualidade de vida.

O conceito de saúde atualmente é muito amplo e se modifica com o tempo. Todos os indivíduos perseguem como objetivo de vida ter saúde. Segundo a Organização Mundial de Saúde, "Saúde é o estado do mais completo bem-estar físico, mental e social e não apenas a ausência de enfermidade”. De acordo com a Constituição Federal (1988), em seu artigo 196: “A saúde é direito de todos e dever do Estado, garantido mediante políticas sociais e econômicas que visem à redução do risco de doença e de outros agravos e ao acesso universal e igualitário às ações e serviços para a promoção, proteção e recuperação”.

Pode-se perceber que a saúde assume um conceito mais ampliado e que se aproxima da qualidade de vida. Para uma vida equilibrada e com qualidade, faz-se necessário um organismo bem nutrido. Nutrição é a ingestão de alimentos, tendo em conta as necessidades alimentares do corpo. Uma boa nutrição - uma dieta adequada e equilibrada, combinada com atividade física regular - é fundamental para uma boa saúde. A má nutrição pode levar à redução da imunidade, aumento da suscetibilidade a doenças, prejudicando o desenvolvimento físico, mental e redução da produtividade (OMS, s/d).

Para completar este trinômio, qualidade de vida é entendida como "a percepção do indivíduo de sua posição na vida no contexto da cultura e sistema de valores nos quais ele vive e em relação aos seus objetivos, expectativas, padrões e preocupações" (WHOQOL GROUP, 1994). O conceito também implica no grau de satisfação do indivíduo com seu meio familiar, social e ambiental; de certa forma envolve uma subjetividade e relatividade cultural.

Atualmente, consideram-se alguns aspectos necessários para que o indivíduo tenha boa saúde, uma vida equilibrada e com qualidade, entre os quais: paz, educação, moradia, alimentação, renda, ecossistema saudável, proteção, justiça social e equidade. 
A educação permanente protagonizada pelo idoso na universidade aberta para a terceira idade/UEPG

Este eixo contempla as disciplinas: Dança circular, Dança de Salão, Dança em Linha, Yoga, Tai Chi Chuan e aulas teóricas.

\section{EDUCAÇÃO FÍSICA, ESPORTE E LAZER}

No terceiro eixo que constitui a UATI, volta-se para o esporte e o lazer que integram a vida humana e são promotores da saúde por ser um incentivo às relações sociais, tais como coleguismo, amizade e paixões.

Complementando este eixo, segundo Dumazedier (1973),

[...] lazer é um conjunto de ocupações às quais o indivíduo pode entregar-se de livre vontade, seja para repousar, seja para divertir-se, recrear-se e entreter-se, ou ainda, para desenvolver sua informação ou formação desinteressada, sua participação social voluntária ou sua livre capacidade criadora após livrar-se ou desembaraçar-se das obrigações profissionais, familiares e sociais (DUMAZEDIER, 1973, p.34).

O esporte e o lazer integram a educação ao longo da vida e impactam positivamente na vida dos idosos. Ambos contribuem para a integração e a melhoria da qualidade de vida, muitas vezes devolvendo às pessoas deste grupo etário condições de mobilidade, melhorias no condicionamento físico e na autoestima.

A educação permanente preocupa-se com o desenvolvimento integral do indivíduo; assim o esporte, as atividades físicas e o lazer integram e contribuem para a melhoria da qualidade de vida. Este eixo, além de contribuir para a qualidade de vida dos idosos, visa trabalhar a função cardiorrespiratória, a flexibilidade e a força; possibilita as relações e participação em grupo, favorece a elevação da autoestima.

Por outro lado, além dos aspectos favoráveis com relação ao idoso, soma-se também o espaço que é criado para a formação de profissionais de Educação Física para trabalharem com este público diferenciado, os idosos, os quais requerem uma metodologia específica e desenvolvimento de atividades relativas às especificidades da idade. Em decorrência disso, desperta o interesse de profissionais para o estudo e pesquisas sobre o envelhecimento humano e em especial sobre a velhice.

São ofertadas diferentes disciplinas neste eixo: Caminhada, Alongamento e Relaxamento, Atividade Esportiva, Hidroginástica, Natação, Pilates de Solo e aulas teóricas.

As referidas disciplinas oportunizam aos idosos a adaptação ao meio líquido (natação), a respiração, aprendizagem de diferentes estilos de natação; o condicionamento físico, a mobilidade articular e recreação. 
A educação permanente protagonizada pelo idoso na universidade aberta para a terceira idade/UEPG

Também é trabalhado o aspecto social e emocional dos idosos, levando-os a alcançar níveis mais elevados de autoconfiança, satisfação, bem-estar psicológico e interação social.

\section{DIREITO, EMPODERAMENTO E CIDADANIA}

No quarto eixo, considera-se que a educação assume função importante para auxiliar na superação de situações de vulnerabilidade com que se defrontam os idosos. O envelhecimento conduz a uma mudança significativa nos papéis sociais, que precisam de uma ressignificação tanto no nível micro, a família, como no nível macro, a sociedade.

A educação é um meio de libertação, empoderamento do idoso, por meio da aquisição de conhecimentos, de atualização, visando a uma vida mais saudável, ativa e participativa. Por meio da integração social, busca propiciar um crescimento pessoal e intelectual ao idoso, superando a conotação de educação como assistencialismo ou infantilização, possibilitando o pleno exercício da cidadania.

O idoso, quando instrumentalizado com conhecimentos, busca a superação de sua vulnerabilidade e dos desequilíbrios sociais, por meio do desenho de um novo paradigma de velhice. Torna-se necessária a transformação progressiva do papel social do idoso, esboçando a possibilidade de seu reconhecimento como sujeito psíquico existente e como agente social, permitindo uma outra maneira de redimensionamento da inserção dos idosos na ordem da temporalidade, delineando a possibilidade de dimensão de futuro.

Neste eixo, há as disciplinas de Informática, Estágio de Inserção Comunitária e aulas teóricas. Há também os projetos Jornal da UATI, Horta da UATI, Projeto de Revitalização e Paisagismo: adote uma manilha.

Os dois cursos que compõem o Programa da UATI são: Curso da Universidade Aberta para a Terceira Idade (UATI) e Curso da Universidade Continuada para a Terceira Idade (UCTI).

\section{CURSO UATI}

O Curso UATI, criado em 1992, possui carga horária mínima de 240 horas, seguindo o calendário universitário. Estrutura-se com abordagem multidisciplinar e analisa constantemente a problemática do idoso nos diversos aspectos: biopsicológicos, filosóficos, político, espiritual, religioso, econômico e sociocultural. 
A educação permanente protagonizada pelo idoso na universidade aberta para a terceira idade/UEPG

Como os idosos têm a possibilidade de eleger as atividades em que estarão envolvidos, a carga horária anual pode ser diferente da estabelecida (ampliada). Os alunos do Curso UATI têm como atividades obrigatórias as aulas teóricas e o estágio de inserção comunitária.

A UATI promove as relações intergeracionais, priorizando o processo de valorização humana e social da pessoa idosa, pela aquisição de conhecimentos e aprimoramento de habilidades oportunizadas em diferentes espaços educativos. Uma das preocupações é possibilitar a melhoria na qualidade de vida, além de uma maior integração e participação social do idoso.

A matrícula para o Curso UATI ocorre no início de cada ano letivo, com data prevista pela coordenação de curso. O critério para ingresso no curso é ser alfabetizado e ter 60 anos ou mais. Não há seleção para ingresso, havendo o preenchimento das vagas ofertadas de acordo com a ordem de chegada para a matrícula.

Devido ao seu reconhecimento na comunidade, há uma grande procura por vagas no curso, havendo a necessidade de lista de espera, pois as vagas ofertadas anualmente são preenchidas com muita rapidez.

Após o término das atividades do Curso, nos três semestres, há a solenidade de formatura, com entrega dos certificados (atualização e participação na UATI). Os alunos que optarem por permanecer no Programa UATI após a formatura passam a frequentar o Curso UCTI.

\section{CURSO UCTI}

A Universidade Continuada para a Terceira Idade (UCTI) é um curso criado em 1994, que oferece aos idosos a possibilidade de continuar com a participação no Programa UATI, considerando que o critério de ingresso é ter cursado integralmente e concluído o Curso UATI.

Os Cursos UATI e UCTI se estruturam com as mesmas disciplinas, favorecendo desta maneira a integração dos idosos das diferentes turmas que se inserem no Programa.

A UCTI não possui limite de anos para ser cursada e vai ao encontro do interesse e da disponibilidade de cada idoso. Assim, registram-se alguns idosos com mais de 20 anos de inserção no Programa.

Relevante também considerar que algumas disciplinas são isentas de mensalidade, mas não da responsabilidade do idoso que, ao se inscrever, deve se comprometer a cursá-las. As disciplinas são: Seresta, Teatro, Caminhada, Atividade Esportiva, Arte e Cultura Gaúcha, Brinquedos e brincadeiras. 
A educação permanente protagonizada pelo idoso na universidade aberta para a terceira idade/UEPG

No Curso UCTI, os idosos não frequentam a disciplina de Estágio de Inserção Comunitária. As aulas teóricas correspondem a uma disciplina obrigatória do Curso UATI, assim não há possibilidade de matrícula nesta disciplina pelos alunos da UCTI. Porém, devido à grande procura pelas aulas teóricas, a cada semestre, há pelo menos 3 aulas teóricas abertas para todos os alunos do Programa, previamente agendadas e divulgadas pela coordenação.

A matrícula e a opção pelas disciplinas ocorrem anualmente, assim, os idosos devem realizar suas escolhas de acordo com as suas preferências, respeitando os horários de cada uma delas e o local de execução. A troca de disciplinas não é permitida no decorrer do ano letivo. Há apenas a possibilidade de desistência e opção de troca na metade do ano, antes do início do $2^{\circ}$ semestre, desde que com justificativa plausível. Nestes casos, é necessária a devida comunicação e autorização da coordenação.

\section{ATIVIDADES DO PROGRAMA UATI}

Para maior entrosamento entre os 600 idosos do Programa UATI, existe o Grêmio da Universidade Aberta da Terceira idade (GUATI), cuja diretoria é escolhida anualmente no mês de julho, com as atribuições principais de oferecer festas anuais, a saber: Festa da Integração do Calouro, Festa do Dia das Mães, Festa Junina, Festa da Primavera (Fantasia ou Anos Dourados) e Festa de Encerramento ou Natalina.

As festas são resolvidas pela diretoria do Grêmio, considerando, além da temática, as atividades que serão desenvolvidas como bingo, desfiles, danças e sorteios de brindes. A organização das festas fica sob responsabilidade do Grêmio e sob a orientação da coordenadora do Programa.

As festas possuem o objetivo de integrar os alunos da UATI, os egressos, e divulgar o Curso, almejando atrair futuros alunos.

Além das festas, há passeios e viagens, que objetivam reconhecer os patrimônios culturais locais e sua importância no processo de crescimento e desenvolvimento do espaço em que vivem; construir, em conjunto com a terceira idade, olhares sobre seu patrimônio, partindo de suas experiências pessoais; conhecer as diferentes realidades patrimoniais nacionais e sua vinculação com a preservação da memória.

São realizadas atividades teóricas, acompanhadas de aulas-passeio para o reconhecimento de diferentes patrimônios culturais. As visitas e viagens se configuram em atividades com cunho pedagógico e cultural. 
A educação permanente protagonizada pelo idoso na universidade aberta para a terceira idade/UEPG

AVALIAÇÃO

Durante todos estes 26 anos de existência ininterruptas do Programa da UATI, são realizadas avaliações com os alunos, professores e coordenação. Abrangem a participação, os relatórios orais e escritos dos alunos e dos responsáveis de cada conteúdo teórico ou prático, enfatizando a autorrealização do aluno e sua integração ao meio sociocultural.

As diferentes disciplinas, projetos e atividades da UATI são reformuladas conforme as necessidades e sugestões apresentadas.

A avaliação dos alunos se baseia em dois critérios: aproveitamento e frequência. $\mathrm{O}$ aluno é avaliado por participação nas atividades, a critério de cada professor. Tanto os alunos do Curso UATI quanto os alunos do Curso UCTI participam dos processos avaliativos.

O Programa da UATI, atualmente, também se constitui como objeto de pesquisa de Trabalhos de Conclusão de Curso (Pedagogia, Educação Física, Jornalismo), dissertações na área de Educação e de Ciências Sociais Aplicadas e teses na área da Educação. Ao mesmo tempo, são produzidos diferentes artigos científicos pelos Grupos de Pesquisa: Envelhecimento, maturidade e Velhice e Políticas Públicas, Educação Permanente e Práticas Educacionais na Educação de Jovens, Adultos e Idosos e, como decorrência, registram-se publicações em periódicos indexados e a apresentação em Eventos Nacionais e internacionais, além de vários capítulos de livros. Todas as produções resultam da relevância e do reconhecimento social do programa na comunidade acadêmica em nível nacional e internacional.

\section{CONSIDERAÇÕES FINAIS}

As Universidades Abertas para a Terceira Idade se constituem ações extensionistas das universidades voltadas para os idosos. Atualmente possuem grande aceitação na comunidade acadêmica e na sociedade em geral. Baseiam-se na concepção de educação permanente e na modalidade da educação não formal.

As ações da UATI respondem satisfatoriamente ao avanço significativo do número de idosos no Brasil e oportunizam para a universidade a realização da sua função extensionista, levando o conhecimento produzido na academia para atender as demandas sociais.

As limitações impostas a essas iniciativas extensionistas voltadas para o idoso ainda são significativas porque enfrentam embates com uma visão pejorativa e negativa desta faixa etária construída historicamente e culturalmente consolidada. Além disso, não possuem apoio político, 
A educação permanente protagonizada pelo idoso na universidade aberta para a terceira idade/UEPG

registrada a ausência de políticas educacionais específicas para estas ações e para a faixa etária dos idosos.

Esta ausência de apoio e de reconhecimento da necessidade destas ações educativas para o idoso, refletem na impossibilidade de atendimento de toda a demanda, pois a quantidade de vagas é insuficiente diante do número de idosos. Outro aspecto relevante, que embora prescrita no Estatuto do Idoso o apoio para a criação das UATI ainda um longo caminho deve ser percorrido para que seja efetivo em todas as universidades brasileiras.

Apesar de uma crescente produção científica nas últimas duas décadas atrelada ao crescimento do número de programas, ainda se registra um número muito pequeno de pesquisadores dedicados à educação do idoso. Esta preocupação deve ser endossada pelos órgãos de fomento de pesquisa no Brasil, por meio de editais específicos, contemplando a educação para o idoso como uma temática que está inserida na temática mais ampla.

Além disso, embora com inúmeros debates e ações educativas para o idoso, dentro de uma concepção permanente, em que o homem aprende durante toda a sua vida, ainda existem resistências para a aceitação destas temáticas como categoria relevante de pesquisa e produção acadêmica, seja em periódicos ou eventos científicos (educação do idoso, educação permanente, universidade aberta para a terceira idade).

As UATI se efetivam como ações concretas, materializando a busca do Paradigma de Envelhecimento Ativo, no qual o idoso é reconhecido, valorizado e instigado a participar, a inserir-se socialmente.

O compromisso da superação de estigmas negativos atribuídos à velhice deve ser coletivo, sustentado teoricamente por pesquisas inovadoras, aliadas ao encantamento de novos estudiosos e profissionais das diferentes áreas de conhecimento que se envolvam com esta temática e contribuam para a melhoria da qualidade de vida para esta faixa etária.

\section{REFERÊNCIAS}

BRASIL. Constituição da República Federativa do Brasil. Brasília, 1988.

BRASIL. Lei n. 10741 de 1 de outubro de 2003. Dispõe sobre o Estatuto do Idoso. Brasília, 2003.

CREF1 - RJ-ES. Estatuto do Conselho Regional de Educação Física da $1^{a}$ Região. Disponível em: http://www.cref1.org.br/estatuto_TIT_II.php. Acesso em: 23 de julho de 2012.

DUMAZEDIER, J. Lazer e cultura popular. São Paulo: Perspectiva, 1973. 
MACHADO, E.; POMPEO, W.A.H. Cidadania e (In)Segurança Pública: o papel das polícias na proteção dos direitos do idoso. In: D’ALENCAR, R.S.; POMPEO, W.A.H. A cidadania na perspectiva da velhice; desafios cotidianos para viver com dignidade. Ilhéus: EDITUS, 2016.

MOSQUERA, J. J. M. Educação: novas perspectivas. Porto Alegre: Sulina, 1975.

OLIVEIRA, R. C. S. Terceira Idade: do repensar dos limites aos sonhos possíveis. Campinas: Papirus, 1999.

OLIVEIRA, R. C. S.; OLIVEIRA, F. S.; SCORTEGAGNA, P. A. Universidade Aberta para a Terceira Idade: a extensão como meio de inserção do idoso no contexto universitário. Assis: Storbem, 2012.

OLIVEIRA, R.C.S, SCORTEGAGNA, P.A., OLIVEIRA, F.S Extensão universitária: perspectivas e ações para a terceira idade. In: OLIVEIRA, R.C.S, SCORTEGAGNA, P.A. Universidade Aberta para a Terceira Idade: o idoso como protagonista na extensão universitária. Ponta Grossa: Editora UEPG, 2015.

OLIVEIRA, R.C.S, SCORTEGAGNA, P.A., OLIVEIRA, F.S A Universidade Aberta para a Terceira Idade na UEPG/Brasil: o idoso no contexto extensionista da universidade. In: OLIVEIRA, R.C.S, SCORTEGAGNA, P.A. Universidade Aberta para a Terceira Idade: o idoso como protagonista na extensão universitária. Ponta Grossa: Editora UEPG, 2015.

PINTO, A. V. Sete lições sobre educação de adultos. 16 ed. São Paulo: Cortez, 2010.

SILVA, N.L., VERGARA, M.A., SILVA, R.E. As memórias e saberes de pessoas idosas no espaço universitário: estudo sobre o Núcleo de Pesquisas e Ações da Terceira idade. São Cristóvão: Ed. UFS, 2015.

WHOQOL GROUP. WHOQOL: Measuring quality of life. 1994. Disponível em: < www. who.int/mental_health>. Acesso em 10 jan 2012.

WORLD HEALTH ORGANIZATION (WHO/OMS). Saúde. s/d. Disponível em: http://www.who.int/topics/nutrition/en/. Acesso em 18 de agosto de 2012.

YUNI, J.A. Notas sobre el presente y el devenir de la educación de adultos mayores como proyecto de cambio cultural. In: OLIVEIRA, R.C.S., SCORTEGAGNA, P.A., CURY, M.J.F.A velhice e o envelhecimento no contexto ibero-americano. Cascavel: EDUNIOESTE, 2016. 